\title{
CONTROL OF EARLY-AGE CRACKING IN WATERTIGHT CONCRETE STRUCTURES
}

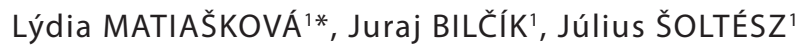

\begin{abstract}
Considering the importance of leaking cracks in terms of serviceability and durability of watertight concrete structures, emphasis is placed on thermal movements and their effect on foundation slabs and walls. Both members are usually restrained to some degree externally and/or internally. The results indicate that restrained thermal stresses are the primary cause of early-age cracks in concrete members.

This paper offers a discussion of mitigation strategies to prevent the formation and propagation of early-age separating cracks. A FEM-based analysis was used to determine the development of stresses in walls on mat foundations in relation to the crack risk assessment.
\end{abstract}

\section{Address}

1 Slovak University of Technology, Faculty of Civil Engineering, Dept. of Concrete Structures and Bridges, Bratislava, Slovakia

* Corresponding author: lydia.matiaskova@stuba.sk

\section{Key words}

- Watertight concrete,

- Foundation slabs,

- Walls,

- Restrained contractions,

- Early-age cracking,

- Reinforcement.

\section{INTRODUCTION}

The various types of cracks are essentially defined by the principal cause or mechanism associated with their function. There are two main reasons of formation and development of cracks in concrete structures subjected to:

- direct loading (structural cracks),

- restraint to imposed deformations (non-structural cracks).

Concrete structures often present volumetric changes particularly due to thermal and moisture related movements. Volumetric instability is detrimental to serviceability and durability of concrete structures because structural elements are usually restrained. When the concrete is restrained from free movements, tensile stresses arise and often result in cracking (Mihashi and Leite, 2004). Volume instability and cracking tendencies are magnified in massive structures due to temperature and moisture variations. This type of cracking is denoted as the "early-age cracking".

Full mitigation of cracks with limited widths in concrete structures is in principal not economical and often not necessary. In the watertight concrete structures (WCS) crack widths are limited for the required performance and durability reasons. Cracking that is caused by an internal restraint (resulting from thermal gradients) is usually localized to the surface and the cracks will often close up as the element cools down. More serious separating cracks arise from external restraint that may lead to seepage or leakage of water (Bamforth, 2007).

\subsection{Strategies for limiting hardening-induced cracks}

The process of concrete hardening is accompanied with temperature and moisture changes due to the hydration of cement and its gradual maturing while being exposed to environmental influences. These changes enforce restrained movements. The expected strains, on the other hand, may be efficiently reduced by constructional, technological and execution measures.

In foundation slabs, the consequences of strain restrictions at the soil-structure interface (shafts, piles, underground walls etc.) appear. The value of strain restrictions of walls monolithically joined to foundation slabs depends on the wall-to-foundation and slab-to-soil stiffness ratios as well as on the length-to-height $(L / H)$ ratio of the cast sections. The tensile stresses can be effectively limited with provision of induced contraction joints. In this way, crack-free wall sections be- 


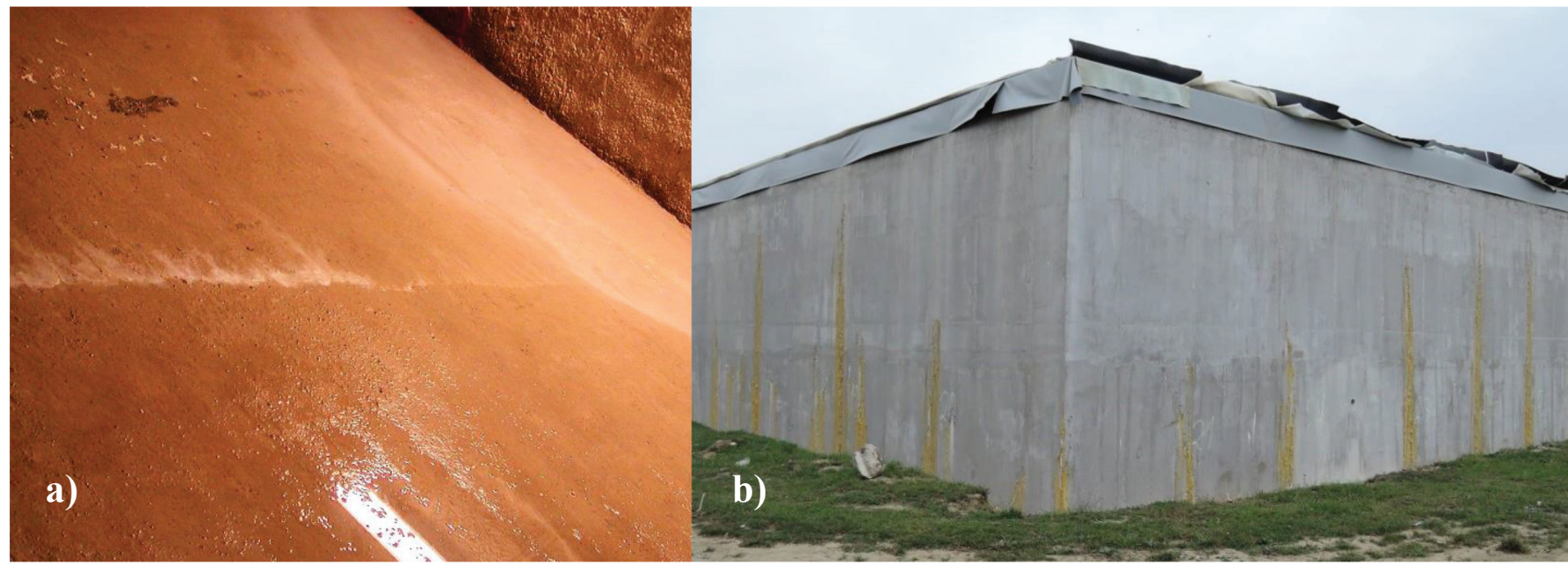

Fig. 1 Water leakage through cracks in: a) a foundation slab; b) an orthogonal tank wall

tween joints may be achieved. The distance between induced contraction joints is specified according to supporting conditions and simultaneously, it should not exceed 2- to 4-times the height of the wall.

Execution of WCS requires compliance with the general requirements applicable to the execution of concrete structures according to EN 13670. Division of the foundation slab and the walls to appropriate sections for casting should be prescribed by the designer, in cooperation with the contractor.

Curing of WCS must also consider the thermo-technical aspects. Cooling of concrete parts in WCS that are designed without cracks should be regulated so that the actual strength of concrete is always greater than the tensile stresses resulting from the restrained contraction.

\section{WALLS RESTRAINED BY THE FOUNDATION}

The most recognizable form of edge restraint occurs when a wall is cast onto a rigid foundation. In the beginning, compression stresses arise in the wall due to the increase in hydration heat release. As the temperature of concrete drops, the hardening wall tends to shorten. However, at the same time, its movement is restrained along the horizontal joint with the foundation slab. This results in tensile stresses. Thermal early-age cracks occur when the contraction-induced stresses exceed the tensile strength of concrete.

Concerning restraint factors and their determination, several analytic methods have been proposed to this day. Most of them are based on the compensation plane method, where the restraint factors and induced stresses are determined according to the stiffness ratios of hardening members and the adjacent restraining bodies. The well-accepted approaches based on this method are presented in JSCE (2007), ACI Report 207 (2007) and EN 1992-3 (2006) and further advanced in recommendations such as CIRIA C660 (Bamforth, 2007) and others.

The above-mentioned methods are used in absence of more accurate calculations. These solutions generally lead to straightforward results, however, the simplifications adapted in their model schemes introduce design uncertainties. For example, according to the recommendations in EN 1992-3, the average restraint value at the wall bottom is defined as 0.5 . On the other hand, a difference in restraint of 0.1 from this mean value affects the level of restrained strain by $20 \%$. Thus, for the cases where the crack width is critical, it is recommended to conduct a more rigorous assessment of the restraint (Bamforth et al., 2010).
Despite of the general agreement with simplifications such as the partial bottom restraint with the axial and bending restraint being determined separately, results on the safe side may not always be expected. Consistently safe results are returned only in case a full bottom restraint and the Poisson's ratio equal to 0 is presumed. The restrained stresses at the wall bottom $\sigma_{\mathrm{ct}}$ reach values independent from the $L / H$ ratio, whereas the stress distribution over the height changes according to the given geometry. The stresses in the crown increase with the increasing $L / H$ ratio, see Fig. 2. Naturally, this approach returns high values of tensile stresses at the wall bottom and thus engineers prefer analytical models allowing for a partial bottom restraint.
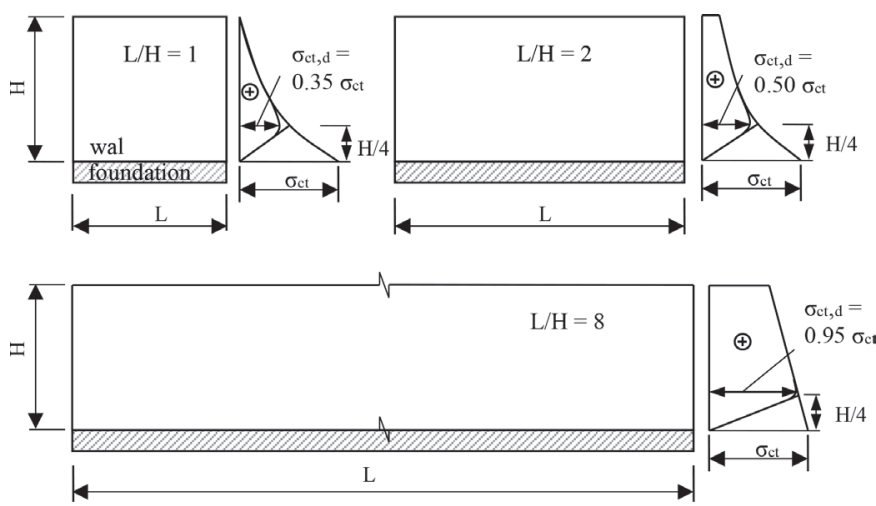

Fig. 2 Tensile stresses from a temperature decrease in walls of various $L / H$ ratios with the full bottom restraint and neglected Poisson's ratio (adapted from Lohmayer and Ebeling, 2009)

According to findings in (Schlicke et al., 2018), the magnitude of stresses and their distribution over the height of walls with a partial bottom restraint is strongly influenced not only by their $L / H$ ratio but also by the geometry of the restraining slab and the position of the center of gravity in the wall-to-slab cross section. The correct determination of the restraining degree is the most pronounced in short walls on foundations of smaller thickness. Here, overall lover values of restrained stresses increase significantly towards the wall bottom until they exceed the values of stresses in walls with higher $L / H$ ratios. The explanation lies in the global bending moment which relieves a part of the tensile stresses in the bottom area of longer walls. For this reason, it is recommended to determine the restrained stresses in models with realistic restraining conditions, e.g. in numerical models. 


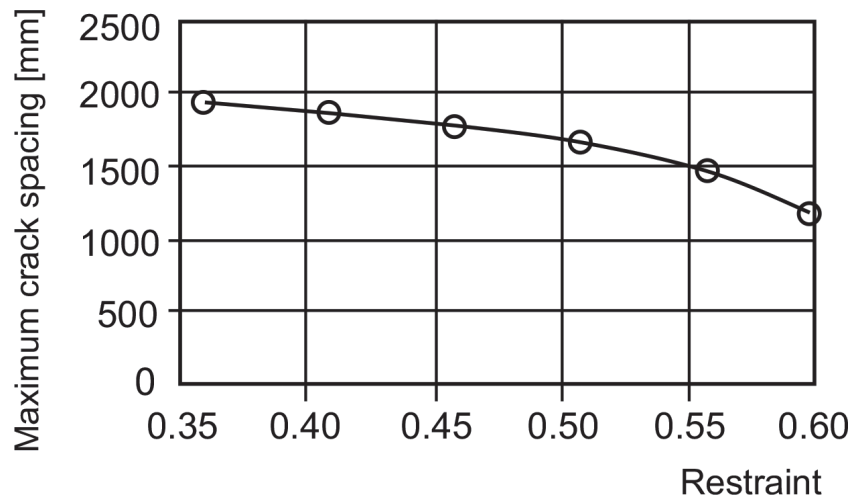

Fig. 3 Relationship between crack spacing and restraint (Bamforth et al., 2010)

If cracks occur, the vertical separating cracks in walls propagate from the bottom construction joint. Often extending in length of several meters, these cracks may stretch to the crown and reach greater widths. Such cracking occurs in walls with $L / H \geq 2-2.5$ (Rostásy 1998). The crack spacing (and hence the crack width) and restraint are linked - a higher edge restraint will reduce the crack width, see Fig. 3.

\subsection{Influence of geometry on the risk of cracking}

As mentioned above, geometry and evolution of stiffness of both the hardening walls and the restraining bodies have a major influence on the course of early-age stresses and the subsequent development of cracks. The magnitude of induced stresses depends on the degree of restraint $\alpha_{\mathrm{R}}(t)$. The degree of restraint depends on both the slenderness ratio $L / H$ and the stiffness ratio of the hardening wall and the restraining foundation:

$$
\alpha_{\mathrm{R}}(t)=\left(L / H ; \frac{A_{\mathrm{w}} E_{\mathrm{w}}(t)}{A_{\mathrm{f}} E_{\mathrm{f}}(t)}\right)
$$

As the moduli of elasticity $E_{\mathrm{w}}(t)$ and $E_{\mathrm{f}}(t)$ are time-dependent variables, the degree of restraint evolves correspondingly. For this reason, an accurate determination of the degree of restraint with analytic approaches may be problematic. Thus, a more detailed crack risk assessment requires FEM based simulations with time-discrete material and mechanical models.

The stiffness ratios were found to be the primary factors determining the induced restraint actions (Rostásy,1998). The final course of stresses, however, results from the coupled action of hardening-induced restraint stresses and stresses arising from the deformation compatibility of the whole structure (Schlicke, 2015; Schlicke et al., 2018).

In engineering practice, the geometry of structures is based on their structural performance and the time scheduling of pours is often dependent on the individual limits at the building site. For this reason, the simplest approach for controlling the evolution of stresses might be the prescription of pouring sizes and provision of adequate curing. The influence of pouring sizes expressed through the relation of the slenderness ratio $L / H$ and the risk of cracking in walls on foundations was examined in the following numerical study.

\subsection{Numerical study}

A numerical study was performed on 5 walls with the slenderness ratios $L / H$ of $0.5,1,2,4$ and 8 . As the slenderness ratio was the major influencing factor, contribution of the stiffness ratio was minimalized with consideration of equal section ratios $A_{\mathrm{w}} / A_{\mathrm{f}}$. The considered geometry characteristics are summarized in the Tab. 1 and Fig. 4 (left).

Tab. 1 Geometry characteristics

\begin{tabular}{|c|c|c|c|c|c|c|c|c|c|}
\hline \multirow{2}{*}{ no. } & $H_{\mathrm{w}}$ & $B_{\mathrm{w}}$ & $A_{\mathrm{w}}$ & $H_{\mathrm{f}}$ & $B_{\mathrm{f}}$ & $A_{\mathrm{f}}$ & $A_{\mathrm{w}} / A_{\mathrm{f}}$ & $L$ & $L / H_{\mathrm{w}}$ \\
\hline & {$[\mathrm{m}]$} & {$[\mathrm{m}]$} & $H_{\mathrm{w}}{ }^{*} B_{\mathrm{w}}\left[\mathrm{m}^{2}\right]$ & {$[\mathrm{m}]$} & {$[\mathrm{m}]$} & $H_{\mathrm{f}} * B_{\mathrm{f}}\left[\mathrm{m}^{2}\right]$ & [-] & {$[\mathrm{m}]$} & {$[-]$} \\
\hline 1 and 2 & 6 & \multirow{2}{*}{0.5} & 3 & \multirow{2}{*}{1} & 6 & 6 & \multirow{2}{*}{0.5} & 3 and 6 & 0.5 and 1 \\
\hline $3,4,5$ & 3 & & 1.5 & & 3 & 3 & & $6,12,24$ & $2,4,8$ \\
\hline
\end{tabular}
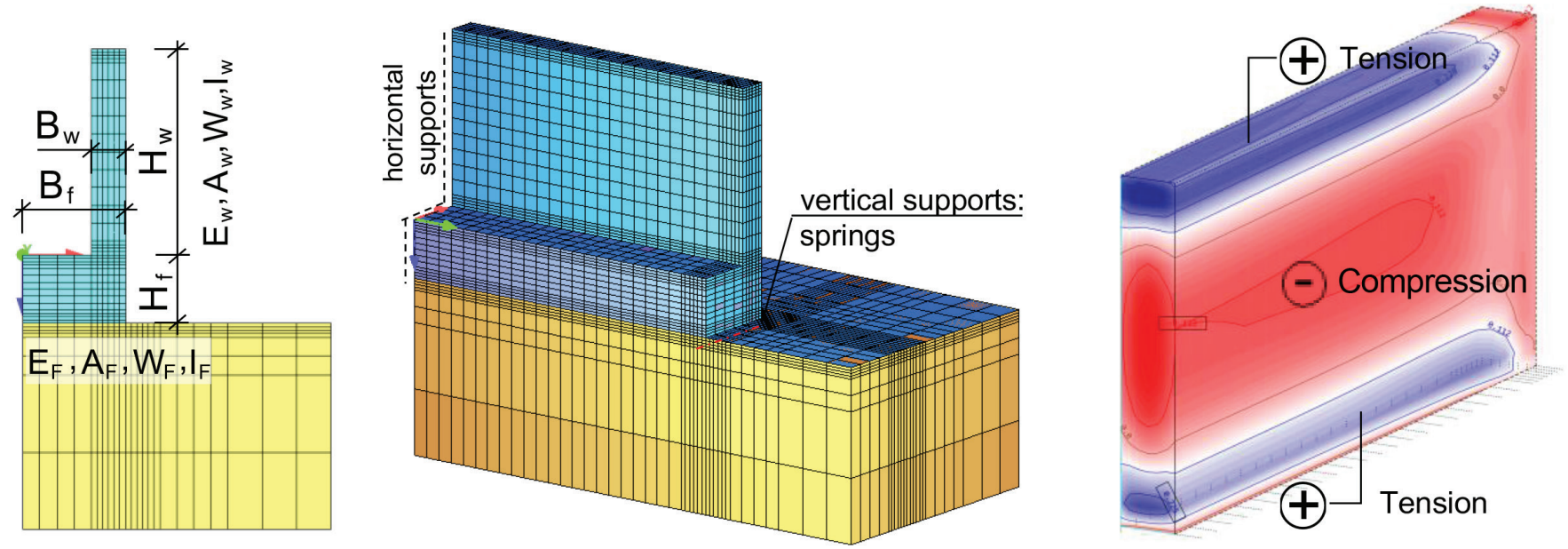

Fig. 4 Model visualization (left). An illustrative example of the resulting longitudinal stresses in the wall, case L/H=4, cool down period (1.5 days after casting). Core under compression, top and bottom under tension (right) 
Tab. 2 Parameters entering the analysis

\begin{tabular}{|c|c|c|c|c|c|}
\hline \multicolumn{4}{|c|}{ Material, thermal and physical parameters } & Concrete & Dry soil \\
\hline \multicolumn{2}{|c|}{ Thermal conductivity } & $\lambda$ & $\mathrm{W} /(\mathrm{m} \cdot \mathrm{K})$ & 2.4 & 0.3 \\
\hline \multicolumn{2}{|c|}{ Specific heat } & $\mathrm{c}_{\mathrm{b}}$ & $\mathrm{kJ} /(\mathrm{kg} \cdot \mathrm{K})$ & 1.1 & 0.675 \\
\hline \multicolumn{2}{|r|}{ Density } & $\rho$ & $\mathrm{kg} / \mathrm{m}^{3}$ & 2500 & 1800 \\
\hline \multirow{2}{*}{ Coefficient of heat exchange } & Covered surface - plywood formwork & \multirow{2}{*}{$\alpha_{\mathrm{p}}$} & \multirow{2}{*}{$\mathrm{W} /\left(\mathrm{m}^{2} \cdot \mathrm{K}\right)$} & 3.6 & - \\
\hline & Free surface & & & 6.0 & 1.5 \\
\hline \multicolumn{2}{|c|}{ Thermal expansion coefficient } & $\alpha_{\mathrm{T}}$ & $1 / \mathrm{K}$ & $10-5$ & \multirow{6}{*}{-} \\
\hline \multirow{3}{*}{$\begin{array}{l}\text { Parameters for the heat } \\
\text { release calculation }\end{array}$} & Cement content & $\mathrm{C}_{\mathrm{c}}$ & $\mathrm{kg} / \mathrm{m}^{3}$ & 300 & \\
\hline & Potential heat of hydration & $\mathrm{Q}_{\text {pot }}$ & $\mathrm{J} / \mathrm{g}$ & 330 & \\
\hline & Maximum heat of hydration & $\mathrm{Q}_{\infty}$ & $\mathrm{kJ} / \mathrm{m}^{3}$ & 99000 & \\
\hline \multirow{2}{*}{ Concrete mixture } & \multicolumn{2}{|l|}{ Aggregate } & $\mathrm{kg} / \mathrm{m}^{3}$ & 1882 & \\
\hline & \multicolumn{2}{|l|}{ Water } & $\mathrm{kg} / \mathrm{m}^{3}$ & 160 & \\
\hline
\end{tabular}

Both the wall and the foundation are assumed to be constructed using a concrete mixture specifically recommended for watertight basement structures. A slow evolution of heat release and strength properties is characteristic for the used type of cement, CEM IIIB - S $32.5 \mathrm{~N}$. The target concrete grade was C 30/37.

The adjacent body of soil was included in the model as well. Its interaction with the concrete superstructure is, however, limited to thermal exchange only. The support condition for the concrete foundation is defined with a sequence of nonlinear springs with a high stiffness in compression but failure in tension. This kind of support condition allows for positive bending of the foundation slab.

The ambient temperature was $20^{\circ} \mathrm{C}$, without daily fluctuations. The initial temperature of the soil body was $20^{\circ} \mathrm{C}$ and the temperature of the fresh concrete at placing, $25^{\circ} \mathrm{C}$.

The evolution of the strength and deformation characteristics during hardening was assumed for both the foundations and the walls. It was further assumed that the walls were cast 14 days after finishing the foundations. The walls were stripped from their formwork after 3 days. The analysis further depicted another 27 days. For the hardening, a nonstationary thermal field was taken into consideration. All relevant parameters entering the simulation are summarized in the Tab. 2 and the assumed geometry is shown in Fig. 4 (left).

\subsection{Results}

The risk of cracking was determined for all examined walls in the critical cross section where the highest tensile stresses were expected.
In case of solitary walls on foundations, the critical cross section is located at the axis of symmetry.

As the walls were of equal thickness, the temperature evolution and longitudinal temperature gradients in all critical cross sections were similar and thus internal restraint was of minor influence. The maximum temperature in the core reached $48.52^{\circ} \mathrm{C}$ in the wall no. 1 $(L / H=0.5)$ and $48.55^{\circ} \mathrm{C}$ in the wall no. $5(L / H=8)$. A representative temperature evolution is shown in the Fig. 5.

The evolution of stresses and consequently the risk of cracking was studied according to two approaches. In the first approach, the values of stresses in individual nodes of the FEM model were compared to the current value of tensile strength determined according to the effective age in the given nodes. According to expectation, the highest tensile stresses were determined in the nodes located close to the horizontal joint. For the first three studied cases $(L / H \leq 2)$, the most stressed point was located approximately one thickness of the wall $B_{\mathrm{w}}$ above the foundation. For the other two cases, the distance reached up to $1.5 B_{\mathrm{w}}$. When examining the individual time steps and the distribution of tensile stresses, these reached the whole height of the wall's critical cross section in the cases no. 4 and $5(L / H=4$ and $8)$. In the walls no. 1-3 $(L / H \leq 2)$, the tensile stresses occurred near the top of the wall during the heating phase and slowly transformed into compressive stresses at the cooling stage. The induced tensile stresses were, however, rather low and thus did not rise the risk of cracking.

The risk of cracking in the critical node is determined as the ratio between the induced stress and the tensile strength $f_{\mathrm{ctm}}(t)$. A rising tendency with the rising $L / H$ may be concluded, see Fig. 6 .

The major driving force behind formation of stresses in walls

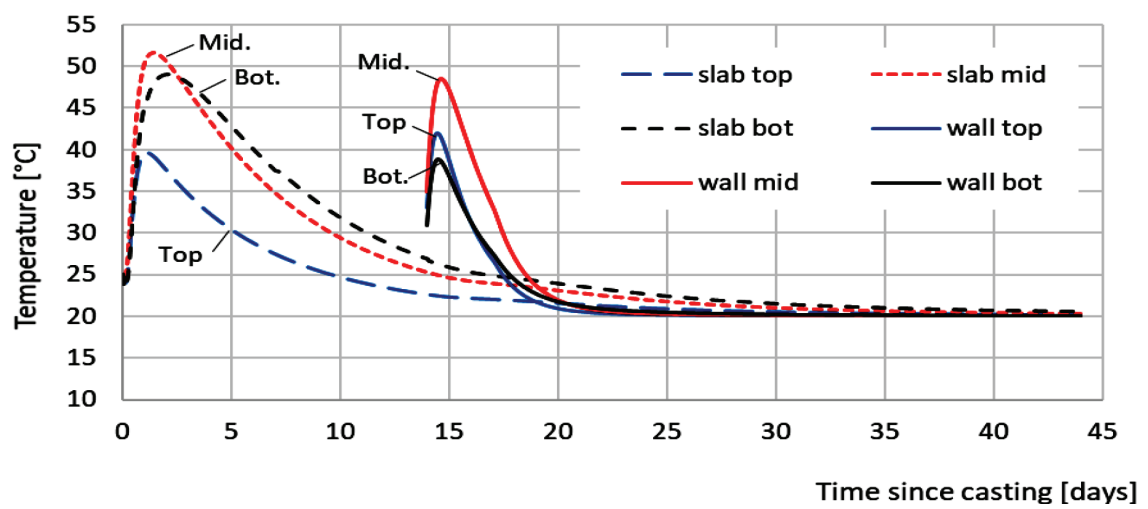

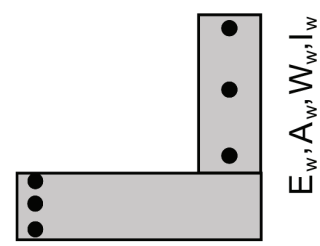

$E_{F}, A_{F}, W_{F}, I_{F}$

Fig. 5 Temperature evolution, case no. 4 (left) and location of the control nodes (right) 
restrained by foundations is the sequence of temperature deformations restrained by the rigid connection between the two structural elements. This introduces a centric and bending restraint to the hardening member. Assuming that both members are monolithically connected, the occurring deformations coincide and add up in the global stress resultants. In another words, during the cool-down period, a homogenous deformation impact from contraction of the wall along with a possible deformation impact from vertical temperature gradients, introduce tensile normal forces $N(t)$ as well as inner positive bending moments $M(t)$ in the cross sections of both, the wall and the foundation slab.

In agreement with the above stated, the second approach for determining the risk of cracking represents the consideration of cross section stress resultants with the actual average tensile strength $f_{\mathrm{ctm}}(t)$ and simultaneously, with exclusion of residual stresses due to development of microcracks as recommended in (Schlicke, 2015):

$$
\frac{N(t)}{A} \pm \frac{M(t)}{W} \leq f_{\mathrm{ctm}}(t)
$$

The nodal stress peaks in this case serve for assessing the occurrence of localized microcracks that lead to softening of the cross section and consequential relief of residual stresses. Microcracking could not be excluded in all considered cases as the induced tensile stresses exceeded the recommended limit of $0.8 f_{\text {ctko,05 }}(t)$. In this contribution, only the risk of macrocracking cracking in walls is presented (Fig. 6 and Fig. 7).

With the contribution of residual stresses, the resulting course of stresses is nonlinear, as shown on the right side of Fig. 6. After the exclusion of residual stresses, the course of stresses becomes linear (resulting from the normal force and the bending moment) and the most stressed area locates at the bottom edge (Schlicke, 2015). The determined risk of cracking took a different course as compared to the previous assessment in nodes, see Fig. 7. A slight increase was found in cases no. $3(+1.4 \%)$ and $4(+0.1 \%)$, whereas for the case no. 5, the consideration of stress resultants led to a substantially decreased risk of cracking $(-17.5 \%)$. In cases no. 1 $(-33.1 \%)$ and $2(-23.4 \%)$, a decreased risk of cracking was observed as well. The linear distribution of stresses over the height thus shall be considered for each case separately as it may lead to diverse results.

The most valuable outcome of the presented analysis is a realistic determination of the magnitude of inner forces, with consideration of an evolving degree of restraint and deformation compatibility. This may serve as a mechanically based approach for design of reinforcement for crack width control as opposed to approaches based on analytical methods.

It should be noted, however, that effects of shrinkage and creep were not considered at this stage. Shrinkage-induced strains in walls might lead to significant stresses.

\section{CONCLUSION}

The necessity, extent and kind of mitigation strategies for limiting restrained early-age strains may be successfully verified with suitable numerical models. In this contribution a commonly applied measure of limiting $L / H$ was examined. It was emphasized that for a
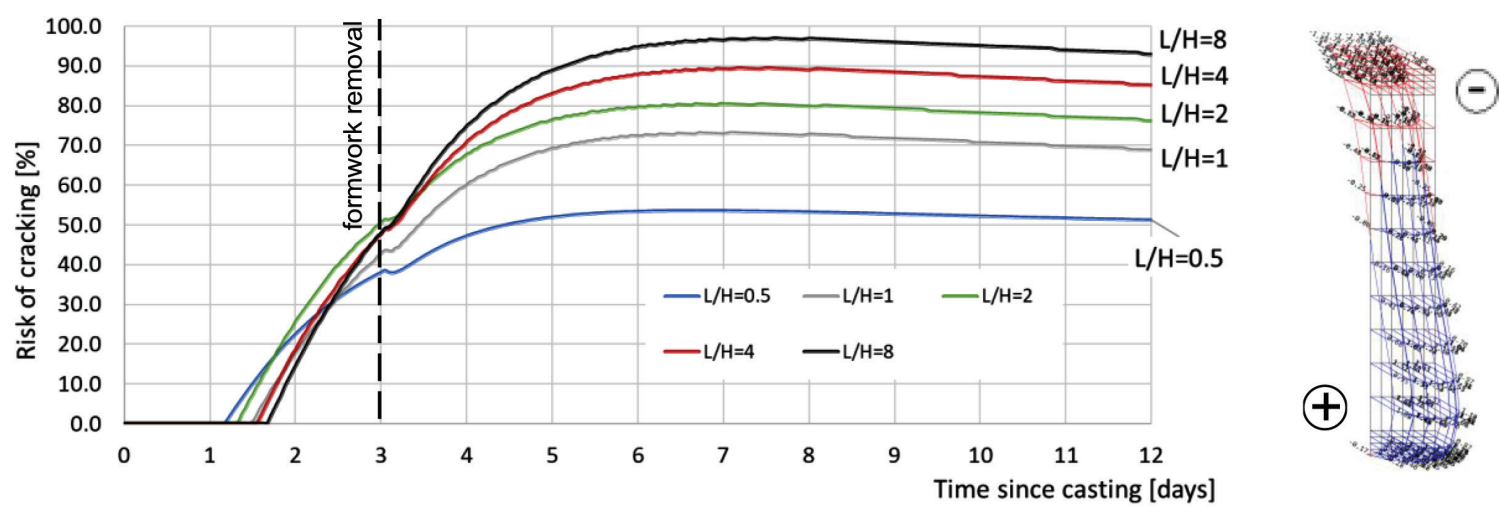

Fig. 6 Comparing the risk of cracking in the critical node (left)

An example of the nonlinear distribution of longitudinal stresses over the height in the critical cross section, case $L / H=4,4$ days after casting. The most stressed point is located approximately $B_{w}$ above the bottom connection. The tensile stresses decrease towards the bottom due to the contribution of residual stresses (right).

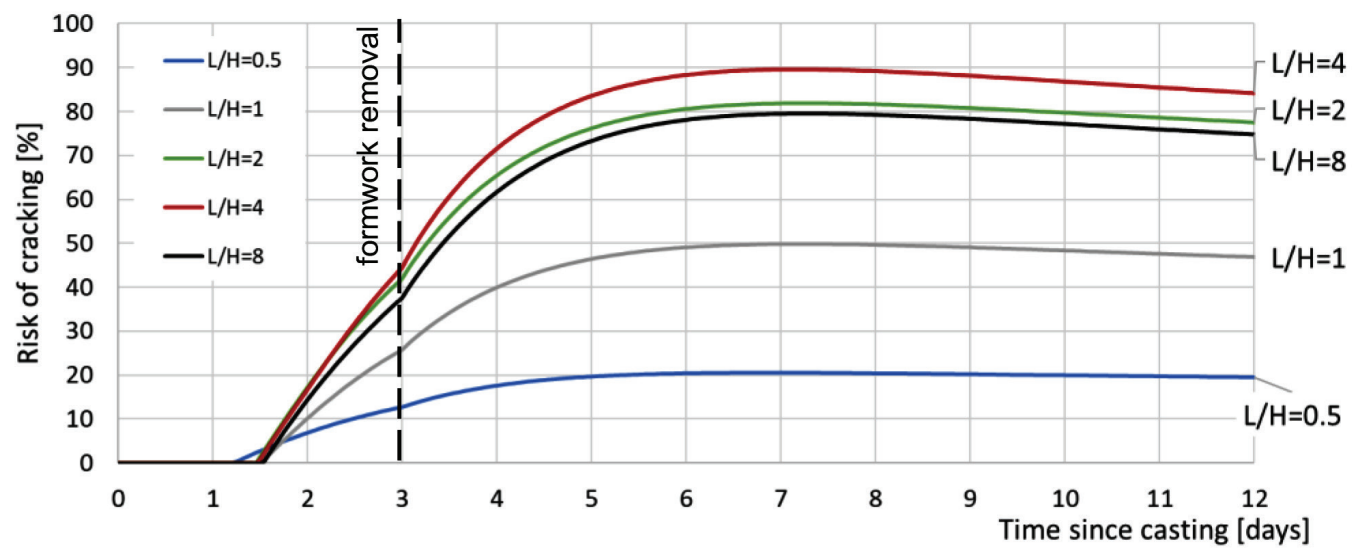

Fig. 7 Comparing the risk of cracking from the stress resultants in the critical cross section 
reliable crack-risk assessment, a time-discrete evolution of the degree of restraint as well as the global deformation behavior have to be taken into account. In agreement with (Schlicke, 2015) it was further recommended to consider the peak nodal stresses for occurrence of microcracking and the stress resultants with exclusion of residual stresses for occurrence of macrocracks.

The risk of cracking differs for assessment with values in nodes and resultants in cross sections. Rising $L / H$ has a direct influence on the increasing risk of microcracking and to some degree of macrocracking deduced from stress resultants. The presented study, however, needs improvements in terms of a suitable consideration of shrinkage strains as well as of a greater number of studied scenarios, e.g. with changing ambient conditions.

\section{Acknowledgements}

This work was supported by the Slovak Research and Development Agency under the contract No. APVV-15-0658 and by the Scientific Grant Agency VEGA under the contract No. VEGA 1/0456/17.

\section{REFERENCES}

ACI Committee 207 (2007) ACI 207.2R-07: Report on thermal and volume change on cracking pf mass concrete. American Concrete Institute, 28 pp., Farmington Hills, MI.

Bamforth, P. B. (2007) Early-age thermal crack control in concrete. CIRIA C660, London.

Bamforth, P. - Denton, S. - Shave, J. (2010) The development of a revised unified approach for the design of reinforcement to control cracking in concrete resulting from restrained contraction. ICE Research Project 0706, 67 pp.

EN 13670 CEN (2004) Execution of concrete structures, 64 pp., Brussels.

EN 1992-3 CEN (2006) Design of concrete structures. Part 3: Liquid retaining and containment structures. 24 pp. Brussels.

JSCE (2007) Guidelines for Concrete. No. 15: Standard Specifications for Concrete Structures: Design. Japan Society of Civil Engineers, Tokyo, Japan.

Lohmayer, G. - Ebeling, K. (2009) Weisse Wannen einfach und sicher. 9 überarbeitete Auflage, Verlag Bau + Technik, 461 pp. (in German)
Mihashi, H., - de B. Leite, J.P. (2004) State-of-the-Art Report on Control of Cracking in Early Age Concrete. Journal of Advanced Concrete Technology, 2(2), pp. 141-154.

Rostásy, F. S. - Tanabe T. - Laube M. (1998) Assessment of External Restraint. In: Prevention of Thermal Cracking in Concrete at Early Ages. E\&FN SPON, London, UK, pp. 149-177.

Schlicke, D. - Tue, N. V. (2015) Minimum reinforcement for crack width control in restrained concrete members considering the deformation compatibility. Structural concrete 16, pp. 221-232, DOI: 10/1002/suco.201400058

Schlicke, D. - Matiašková, L. - Šoltész, J. (2018, in print) Influence of Partial Restraining Conditions and Poisson's Effect in Bottom-Restrained Walls. SynerCrete'18 International Conference on Interdisciplinary Approaches for Cement-based Materials and Structural Concrete, 24-26 October 2018, Madeira Island, Portugal 